\title{
¿Por qué acudir a la literatura para recrear la configuración del perdón en el conflicto armado interno colombiano?
}

\author{
Jorge Eduardo Vásquez Santamaría** \\ Catalina Merino Martínez $z^{* * *}$ \\ Estefanía López Salazar ${ }^{* * * *}$
}

Yo canto para él, construyo lo presente sobre lo pasado (como un árbol vivaz sobre sus raíces, así lo presente sobre lo pasado), hago que él se infunda en el tiempo y en el espacio, y que en él se unan las leyes inmortales, para que, con ellas, se haga su ley propia.

Walt Whitman

* Artículo de investigación. Resultado del proyecto "Las narrativas del perdón desde los géneros literarios en Colombia", adscrito a la línea de investigación Derecho, Conflicto e Internacionalización, del grupo de investigaciones Orbis luris, Facultad de Derecho, Fundación Universitaria Autónoma de las Américas, Medellín, Colombia. Citar como: Vásquez, J, Merino, C y López, E. (2018). ¿Por qué acudir a la literatura para recrear la configuración del perdón en el conflicto armado interno colombiano?. Hallazgos, 15(30), 19-44. DOI: https://doi.org/10.15332/2422409X.4802

** Abogado y Magister en Derecho de la Universidad de Medellín. Especialista en Derecho Administrativo de la Universidad Pontificia Bolivariana, y en Docencia Investigativa Universitaria de la Fundación Universitaria Luis Amigó. Líder del grupo de investigaciones Orbis luris, Facultad de Derecho de la Fundación Universitaria Autónoma de las Américas. Interviene como investigador principal. ORCID: http://orcid.org/0000-0002-6280-005X Contacto: jorge.vasquez@uam.edu.co

*** Abogada de la Universidad de Antioquia y especialista en derecho de familia de la misma universidad. Magister en derecho procesal y doctoranda en derecho procesal contemporáneo de la Universidad de Medellín. Docente investigadora de la Facultad de Derecho de la Fundación Universitaria Autónoma de las Américas (2017). Intervino como investigador principal. ORCID https://orcid.org/0000-0002-4143-1865 Contacto: catalina.merino@ uam.edu.co

**** Abogada de la Universidad Autónoma Latinoamericana. Magister en escrituras creativas de la Universidad Eafit. Docente investigadora en la Facultad de Derecho de la Corporación Universitaria Americana sede Medellín. Interviene en el proyecto de investigación como asesora externa. ORCID https://orcid.org/0000-0003-1168-8835 Contacto: estefalosa@gmail.com 


\section{RESUMEN}

Hablar de posacuerdo implica comprender que la paz no surRecibido: 12 de febrero de 2018 ge de la convención formal entre actores en conflicto, sino de la reconstrucción lenta de una sociedad fragmentada por el dolor a partir de la interacción y el perdón entre víctimas y victimaAceptado: 12 de mayo de 2018 rios. Por ello, el perdón emerge como elemento imprescindible para la reestructuración de la civilidad, y una de las maneras posibles de alcanzarlo se encuentra en la literatura, testimonio ético-político que deja huella del acontecimiento en la memoria colectiva y constituye el escenario propicio para el encuentro y la afirmación de la otredad y de la memoria. Con la literatura como escenario se propuso la pregunta: ¿cómo se ha configurado el perdón a partir de los géneros literarios dentro del conflicto armado interno en Colombia (1948-2016)? Interrogante desde el cual se analizaron las distintas configuraciones que ha asumido el perdón a partir de los géneros literarios en el desarrollo del conflicto armado interno. Con el perdón, el conflicto, las narrativas y los géneros literarios como categorías predefinidas de investigación se ejecutó una metodología soportada en el modelo cualitativo, con enfoque histórico-hermenéutico y aplicación del método hermenéutico. Dando lugar así a un constructo teórico y reflexivo de la literatura como herramienta potencial para la configuración del perdón en la sociedad en posacuerdo. Este texto se propone entonces responder la pregunta ¿por qué acudir a la literatura para recrear la configuración del perdón en el conflicto armado interno colombiano?

Palabras clave: literatura, crónica, conflicto armado, perdón. 


\section{Why go to literature to recreate the configuration of forgiveness in the Colombian internal armed conflict?}

Received: february 12, 2018

Evaluated: april 13, 2018

Accepted: may 12, 2018

\section{Abstract}

Talking about post-agreement implies understanding that peace does not arise from the formal convention between actors in conflict, but, from the construction, from a society fragmented by pain, from the interaction and forgiveness between victims and victimizers. For this reason, forgiveness emerges as an essential element for the restructuring of civility, and one of the possible ways to achieve it is founded in literature, the ethical-political testimony that leaves an imprint on the event in the collective memory and is the propitious scenario for the encounter and affirmation of otherness and memory. With literature as a scenario, the question was asked: How is forgiveness configured from the literary genres within the internal armed conflict in Colombia (1948-2016)? question from which it gave place to the understanding of the configurations that have had the pardon from the literary genres in the development of the internal armed conflict. With forgiveness, conflict, narratives and literary genres as the predefined categories of research, a methodology based on the qualitative model was implemented, with a historical - hermeneutic approach and application of the hermeneutical method, giving rise to a theoretical and reflexive construct of literature as a potential tool for the demise of society in post-agreement. Why go to literature to recreate the question? What is the origin of the Colombian internal armed conflict?

Keywords: literature, chronicle, armed conflict, pardon. 


\section{Por que acudir à literatura para recriar a configuração do perdão no conflito armado interno colombiano?}

\section{Resumo}

Ao falar do pós-acordo implica compreender que a paz não surge da convenção formal entre atores no conflito, senão da reconstrução devagar de uma sociedade fragmentada pela dor e a partir da interação e o perdão entre vitimas e vitimários. Por isso, o perdão emerge como elemento imprescindível para a reestruturação da civilidade e uma das possíveis maneiras de alcançá-lo encontra-se na literatura, testemunha ética - política que deixa marca do acontecimento na memória coletiva e constitui o cenário propício para o encontro e afirmação do outro e da memória.

Com a literatura como cenário foi proposta a pergunta: Como tem se configurado o perdão a partir dos gêneros literários dentro do conflito armado interno na Colômbia (1948-2016)? Interrogante desde o qual se analisaram as distintas configurações que têm adquirido o perdão a partir dos gêneros literários no desenvolvimento do conflito armado interno. Com o perdão, o conflito, as narrativas e os gêneros literários como categorias predefinidas de pesquisa executou-se uma metodologia suportada no modelo qualitativo, com um enfoque histórico-hermenêutico e aplicação do método hermenêutico.

Dando lugar assim ao construto teórico e reflexivo da literatura como ferramenta potencial para a configuração do perdão na sociedade no pós-acordo. Este texto propõe responder á pergunta por que acudir à literatura para recriar a configuração do perdão no conflito armado colombiano?

Palavras-chave: literatura, crônica, conflito armado, perdão.
Recebido: 12 de fevereiro de 2018

Avaliado: 13 de abril de 2018

Aceito: 12 de maio de 2018 


\section{INTRODUCCIÓN}

En el presente, Colombia afronta un escenario de posacuerdo que no implica de manera consecuente que se encuentre en un terreno de paz, es decir, en un momento de posconflicto. El conflicto no es una denominación que pueda reestructurarse con la simple firma de un acuerdo, requiere la reconstrucción de un nuevo engranaje social que respete las tradiciones, las formaciones sociales y culturales pero que al tiempo, elimine las dependencias nocivas a formas tan corrosivas como las acciones instrumentales, la objetivación del otro y las relaciones de poder. Un país en posacuerdo no ha llegado a una etapa de tranquilidad sino, en cambio, se encuentra ante un gran trabajo de reconfiguración del tejido social. En este sentido, deben implicarse todas las áreas del conocimiento y deben plantearse nuevas formas de entender el conflicto, el futuro y el pasado, con la finalidad de resignificarlo y consolidar un camino alternativo.

Colombia requiere comprender medio siglo de violencia y muerte, y el reposicionamiento de la palabra en remplazo del miedo y el silencio. También la conclusión definitiva de hostilidades, la dejación de las armas, y la socialización de la verdad de los hechos acaecidos en poco mas de cinco décadas de enfrentamiento. Estos factores reavivan multiplicidad de figuras que esperan gestarse, muchas de ellas jurídicamente, para emprender caminos de eficacia y sellar el reconocimiento y la protección de valores supremos de una sociedad que trata de pasar del miedo y el escepticismo a la reconciliación y la confianza.
Son varias las figuras que contienen el potencial de contribuir a la realización de los cometidos supremos en la sociedad colombiana. Entre ellas, la justicia transicional es una de las que mayor carga simbólica tiene para el momento histórico en el que se define el futuro de la nación. El poder que debe ejercer sobre las conductas que definieron la realidad social colombiana en el marco del conflicto y contribuyeron a la construcción de un imaginario colectivo que determina una supervivencia egoísta e indiferente - a raíz de la violencia permanente en sus mas amplias e inimaginables posibilidades - se une a su potencial regenerador y reconciliador a través del encuentro de víctimas y victimarios. Éstos son enlaces visibles de la confrontación, en escenarios de identificación y reconocimiento donde la narración de los hechos, tanto cometidos como padecidos, puede y debe ser un insumo para reconstruir el tejido colectivo desde el rescate de la memoria, pero sobretodo, de la posibilidad de conceder el perdón.

Pero incluso en el enorme poder, tanto real como simbólico, que trata de asegurar la administración de justicia, el perdón como valor supremo que permite rehacer la vida social está lejos de asegurar la verdadera realización de la reconciliación entre las partes históricamente enfrentadas. En las fortalezas de la justicia, transicional y no transicional, las garantías de un perdón puro y eficaz se avizoran como posibilidades remotas inmersas en los devenires propios de la ritualidad fijada por la norma, la negociación y las presiones mediáticas. Aquel perdón puro, el verdadero perdón propuesto por Derridá (2003) se sujeta a 
la condicionalidad de la justicia en su afán de proveer resultados que en oportunidades ofrecen una eficacia simbólica mas no instrumental. ${ }^{1}$ Como señala Nieves, el perdón "no debe tener un propósito, aunque fuera noble y espiritual, ya que dejaría de ser puro. No debe tener ningún sentido, ninguna finalidad, incluso, ninguna inteligibilidad. El perdón no debe ser ni normal, ni normativo, ni normalizador, debería seguir siendo excepcional y extraordinario" (p. 152), pues condicionar la posibilidad del perdón coincide con la imposibilidad de su eficacia (Rueda, 2012).

Lejos estará la sociedad colombiana de alcanzar una posible reconciliación si la construcción de la verdad y la memoria se reservan a los estrados judiciales o a la confianza en las disposiciones normativas. La verdad y la memoria son cimientos necesarios para construir y comprender actos de perdón entre los integrantes de la sociedad sometida a la violencia. Por ello, sin desvirtuar los esfuerzos que debe hacer el ordenamiento jurídico, y en él, los poderes públicos y la sociedad, otras figuras deben emprender el empoderamiento de la sociedad colombiana que se ha mantenido victimizada a lo largo del último medio siglo, para que comprenda el presente a partir de la reconstrucción

De acuerdo a Lozano y Ramírez (2015) jurídicamente la eficacia puede ser asumida desde lo simbólico y lo instrumental. Instrumentalmente la eficacia "examina la adecuación de los resultados de una norma tras su implementación, frente a los objetivos propuestos. Si la norma jurídica tiene la capacidad de producir los efectos deseados, entonces puede decirse que es instrumentalmente eficaz" (Lozano y Ramírez, 2015, p. 4). Cuando la disposición no logra producir el resultado 0 , por el contrario, genera un efecto diferente al previsto da lugar a la eficacia simbólica entendida como el efecto de la norma considerada como símbolo, es decir, el mensaje detrás de una norma que puede o no ser efectiva en su aplicación y en el cumplimiento de los objetivos propuestos explícitamente, pero sí eficaz en términos de algunos otros objetivos no declarados (Lozano y Ramírez, 2015, p. 5). histórica del conflicto, y pueda encontrarse y reconocerse en dicha historia, como sujeto individual y social.

Ese reconocimiento puede ser promovido a través de la literatura como una figura diferente a la normativa y judicial por contener los atributos suficientes para contribuir con la realización de los cometidos supremos en la sociedad colombiana. A través de las narraciones literarias de aquellos que asumieron el deber de mantener viva la realidad de otros, en los cuales hoy el sujeto presente puede leerse y leer a los demás. Así, reconfigurar el sentir y el pensar frente a los actores que han definido la cruenta realidad de un país que hace la apuesta histórica por encontrar a todos los sectores alrededor del potencial del perdón, y aprehender las distintas configuraciones que ha asumido el perdón a partir de los géneros literarios en el desarrollo del conflicto armado interno.

El escenario a partir del cual se busca comprender al perdón, que no es judicial y tampoco normativo, es el literario, y dentro de él, los géneros literarios. Se puede afirmar que la literatura abarca la producción intelectual que emplea al lenguaje como medio de expresión y comunicación a través de los géneros literarios, los cuales constituyen las diferentes categorías en las que se agrupan los textos narrativos, ya sea por su contenido o por su composición. La crónica y la novela son dos ejemplos de modelos de estructuración formal y temática en los que el escritor retrata - a partir de la realidad, en el primer caso, o de la ficción, en el segundola historia de una sociedad con la mayor autenticidad y verosimilitud de que sea capaz.

Con la literatura como escenario posible para contribuir con la realización de los 
cometidos supremos en la sociedad colombiana se propuso la pregunta: ¿Cómo se ha configurado el perdón a partir de los géneros literarios dentro del conflicto armado interno en Colombia (1948-2016)? Desde la cual se dio lugar a la comprensión de las distintas configuraciones que ha asumido el perdón a partir de los géneros literarios.

La investigación se prevé en un trabajo de ejecución planeado en dos fases, cada una centrada sobre objetos de estudio concretos articulados con la pregunta macro de investigación. El primero de los objetos se delimitó a las narrativas del perdón a partir de la crónica como género literario, para el cual se propuso como pregunta: ¿Cómo se ha configurado el perdón en la crónica generada alrededor del conflicto armado interno en Colombia (1948-2016)? El segundo se trabaja a partir de la pregunta: ¿Cómo se ha configurado el perdón en la novela generada alrededor del conflicto armado interno en Colombia (1948-2016)? Ambos objetos se encuentran e integran en el perdón, el conflicto armado interno, las narrativas y los géneros literarios como categorías predefinidas a partir de las cuales es posible la aprehensión de la realidad social propuesta, lo que demandó la elaboración de un constructo teórico y reflexivo de la literatura como herramienta potencial para la configuración del perdón en una sociedad de posacuerdo. De allí que este artículo se proponga abordar la pregunta: ¿Por qué acudir a la literatura para recrear la configuración del perdón en el conflicto armado interno colombiano?

\section{Metodología}

La elaboración del constructo teórico y reflexivo sobre la literatura como herramienta potencial para la comprensión de la configuración del perdón implicó un ejercicio metodológico basado en el modelo cualitativo, alienado con el enfoque histórico-hermenéutico, trabajado desde el perdón, el conflicto armado interno, las narrativas y los géneros literarios como categorías predefinidas reunidas en los textos sometidos a la hermenéutica como método de investigación.

El modelo cualitativo fue acogido por las propiedades de las categorías que integran los objetos de estudio antes mencionados y que se reúnen en los textos literarios. Lo cualitativo resultó imprescindible pues cuando se lleva la investigación a objetos propios de las ciencias sociales, se da un distanciamiento entre el sujeto investigador y el objeto aprehensible; esto configura, en apariencia, una relación de observación que pareciera garantizar un rol neutral ausente de influencias en el objeto, como lo expresan García (1989) y Mella (2003 citados en Saavedra Guajardo y Castro, 2007). Al mismo tiempo los autores reconocen que esa labor es imposible siempre que el investigador no puede indagar un fenómeno social con total y absoluta independencia de él, permeándolo, perturbándolo, aunque sea de forma mínima. Situación que se presenta en la configuración del perdón en los géneros literarios si se tienen presentes las propiedades históricas, afectivas, simbólicas y transformadoras de las categorías que se integran y se sobreponen en los objetos de estudio que reposan en la literatura.

Entonces, por qué acudir a la literatura para recrear la configuración del perdón en el conflicto armado interno, cuando la literatura se propone como una figura que contiene el potencial de contribuir a la 
realización de los cometidos supremos en la sociedad colombiana en el posacuerdo. Lo anterior se responde desde lo cualitativo que permite elaborar un constructo del cual los investigadores no pueden estar apartados, neutrales o pretender una objetividad suficiente mientras enfrentan objetos de estudio integrados por categorías con cargas de significado tan profundas y definitorias en un esquema social.

La aprehensión de la configuración del perdón en la literatura metodológicamente hizo necesario reconocer el poder transmisor y transformador que ésta posee como herramienta social y cultural. Sólo estableciendo ese constructo orientador y reflexivo fue posible indagar las formas en como se han concebido las expresiones del perdón en los géneros literarios, aquellos en los que quedaron narrados los actos de perdón dispuestos a la buena voluntad del otro, actos de liberación del resentimiento, expresiones del deseo de sanar, trascender y restablecer relaciones, superando el temor al castigo, al reproche y la perturbación de la conciencia. Estos cometidos exigieron una vinculación responsable del sujeto cognoscente a través de las pautas rigurosas del modelo cualitativo, pero también facilitaron el aprovechamiento de sus fortalezas epistémicas para dar cuenta del posible potencial objetivo de la pesquisa.

Las pautas rigurosas que guiaron la investigación desde lo cualitativo inicialmente se sustentaron en la propuesta de Cook y Reichardt (1986) a partir de la cual se empleó la comprensión del carácter fenomenológico que permea los objetos de estudio, en el sentido de orientar la configuración del perdón en los géneros literarios como resultado de la exteriorización de la conducta humana, marco de referencia de quien actúa en la presentación del perdón y de quien lo recibe. Igualmente, se empleó lo cualitativo como un modelo de aprehensión de la configuración del perdón en la literatura como expresión de una realidad dinámica, holística, aprehensible desde datos históricos, profundos y reales. El modelo cualitativo orientó el descubrimiento y la aproximación a los datos en fuentes literarias definidas a partir de los géneros en un contexto histórico, delimitado por el origen del conflicto armado interno colombiano y su transformación reciente con el posacuerdo. Develó las potencialidades de la literatura como figura diferente a las ofrecidas por la normativa y el ejercicio judicial, con atributos suficientes para contribuir con la realización de los cometidos supremos en la sociedad colombiana.

Desde López Noguero (2005) apoyado en García Ramos (1996) lo cualitativo se asumió como un modelo con posibilidades de aprehensión humanística, dinámica, descriptiva y crítica, enfocado al significado, alcance y dimensiones del perdón en los géneros literarios en un marco social definido. En este, los textos facilitaron la aprehensión de conceptos con cargas sensibles y descripciones de realidades diversas, aproximando al investigador a la comprensión de las dinámicas del perdón en la literatura como herramienta depositaria y transmisora de ese legado histórico.

Si se tiene presente que el perdón se enmarca por excelencia en las ciencias humanas y sociales como un potencial del comportamiento individual que repercute en las condiciones de la construcción y comprensión de los valores sociales que rigen el devenir 
de una comunidad, el modelo cualitativo resulta ser la plataforma obligada para desplegar una acción tendiente a la configuración del perdón en una elaboración cultural como la literatura. Con ello, se puede explicar por qué se debe acudir a la literatura para recrear la configuración del perdón en el conflicto armado interno, como comparten Ramírez, Arcila, Buriticá y Castrillón (2004), la investigación cualitativa: “toma la vida misma como un todo social, que puede ser observado y objetivado. De esta forma el investigador debe usar su experiencia personal como el elemento más válido de acercamiento a un texto social, en este sentido la artesanía cotidiana se convertirá en su propio centro" (p. 30), lo que se define a partir de las potencialidades de la literatura como una expresión objetivada de los acontecimientos vividos en torno al perdón en el conflicto armado interno colombiano.

El perdón se aborda desde las narrativas construidas en los géneros literarios, lo que no solo concreta una fuente de indagación documental para el ejercicio cualitativo que se pretende, pues su poder se estima aun mayor. Siguiendo a Amar-Rodríguez la consigna narrativa implica "[...] algún tipo de conflicto para que ocurra una sutil evolución en lo que queremos exponer", por lo que proponer un diseño metodológico que incluye el trabajo con narrativas es hacer una apuesta a lo cualitativo e interpretativo, con el propósito de dar a comprender determinados hechos que son contados por un informante con voz propia, en este caso, a través de los géneros literarios, con una singularidad de su recuerdo, de su memoria, de su emoción" (2016, p. 975).

Para ello, el método hermenéutico resultó igualmente necesario, toda vez que exige rastrear los datos y realidades contextuales del perdón en la literatura, buscar el entendimiento del sentido, identificar los conceptos, permitir el surgimiento de nuevas ideas, posibilitar la interconexión y contrastación entre los pensamientos y superar contradicciones. La hermenéutica en su proceso comprensivo descubre qué tipo de hábitos mentales, tradiciones o creencias propias, conocimientos previos o prejuicios posee el lector, no para desterrarlos, sino para que puedan ser usados en la interpretación y contenidos, si en algún momento se convierten en obstáculos que impiden a los textos hablar y decirse.

Los procesos de lectura y hermenéutica tienen lugar en las fuentes literarias, razón que hace de la literatura el escenario que se dinamiza por la pregunta como movilizadora del pensamiento crítico e incluso del juicio, ayuda a entender no sólo lo que el texto dice, sino lo que éste no evidencia, sus significados ocultos. En los textos literarios las preguntas deben tener un sentido, una lógica, un orden y una motivación que surja del texto y, al tiempo, permita develarlo abiertamente. De todo ello que abordar la pregunta: ¿Por qué acudir a la literatura para recrear la configuración del perdón en el conflicto armado interno colombiano?, se enmarque en un ejercicio metodológico guiado por el modelo cualitativo y el método hermenéutico como senderos que conduce a la comprensión del poder transmisor y transformador de la literatura.

\section{LA LITERATURA COMO ESPACIO PLURAL DE MUNDOS}

La literatura es un fenómeno multifacético de textos orales y escritos que conservan 
la memoria de una comunidad y, además, implica una práctica social cuyas reglas de producción y de lectura se transforman histórica y culturalmente. Por eso, se puede afirmar que el significado literario es un resultado dinámico constituido por un sinnúmero de posibilidades, tantas cuantos lectores haya. De ahí que, citando a Martha Nussbaum, se deba entender a la creación literaria como "[...] una capacidad de imaginación receptiva que nos permite comprender los motivos y opciones de personas diferentes a nosotros, sin verlas como extraños que nos amenazan, sino como seres que comparten nuestros problemas y oportunidades" (2001, p. 133).

El texto literario, específicamente la novela, permite que el lector se involucre en el proceso creativo más allá de la función decodificadora del mensaje, pues, como lo enseña Bajtín, la obra literaria se erige en una construcción discursiva, en la que aquel reconoce múltiples voces que se entrelazan para contar una historia desde diferentes perspectivas que confrontan la verdad oficial. En su obra de 1989 El problema de los géneros discursivos, este autor moscovita plantea que, en la novela, es posible que exista un fenómeno polifónico, donde a partir de distintas cosmovisiones sobre la realidad, representadas en las voces de cada personaje, es factible enfrentar y cuestionar el discurso monológico del poder (Álvarez, 2011, p. 148). Este autor sostiene que la novela se constituye en un género discursivo, de carácter cultural, cuyo contenido se construye en la práctica cotidiana del lenguaje trasvasada a la historia que se quiere narrar:

La novela es la diversidad social de lenguajes, a veces de lenguas y de voces individuales, diversidad literaria organizada. Sus postulados indispensables exigen que la lengua nacional se estratifique en dialectos sociales, en modos de expresión de grupos, en jergas profesionales, lenguajes de los géneros, habla de las generaciones, de las edades, de las escuelas, de las autoridades, círculos y modas pasajeras, en lenguajes de los días (incluso de las horas), sociales, políticos (cada día posee su divisa, su vocabulario, sus acentos); cada lenguaje se estratifica interiormente en todo momento de su existencia histórica (Bajtín,1995, pp. 88-89).

En ese sentido, la teoría bajtiana podría desbordar el espectro de la literatura de ficción y extenderse también a esferas de la literatura testimonial, como es la crónica sobre el conflicto y el posconflicto, por ejemplo. Ambas se deben entender como una práctica cultural en donde la obra, para circular en la sociedad, debe constituir un espacio de voces múltiples que permita generar un escenario comunicacional relacionado con el contexto. De tal suerte que, a partir de un encuentro dialógico entre los distintos personajes, o entre el narrador y éstos últimos, se pueden evidenciar las distintas consciencias y saberes presentes en la historia que se narra y que, de alguna manera, da cuenta, por fuera de los esquemas oficiales y unidireccionales de una época dada, de los hechos que se pretenden contar a partir del discurso literario.

En ese sentido, el texto literario ficcional y la crónica como subgénero testimonial, se erigen en canales hermenéuticos del imaginario colectivo, al ser herramientas de denuncia que permiten generar reflexiones sobre conceptos como la verdad y la justicia desde 
el rompimiento de la historia oficial y la inclusión del relato como medio catalizador de lo impuesto a partir de puntos de vista distintos que recrean la realidad. En síntesis, a partir del quehacer literario se construye un puente entre los ciudadanos y la memoria, donde la narración es una herramienta de reivindicación humana y social. La literatura es un escenario de subversión crítica, porque permite una reflexión de los asuntos jurídico-sociales desde otra óptica menos rígida, menos castradora, menos heredada y preconcebida, que permite reconstruir subjetividades y reorientar la visión del mundo. Ya lo decía Bajtín, la polifonía en la narración - la sincronía de la voz del autor, del narrador, de los personajes - es una "recreación artística de la naturaleza polifónica de la propia vida" (1995, p. 276), que permite a través del arte una conexión dialógica entre los sujetos y las conciencias.

En términos generales, se puede afirmar que la literatura es un concepto que abarca aquella producción intelectual que usa al lenguaje como vehículo de expresión y comunicación a través de los llamados géneros literarios, que son las diferentes categorías en las que se agrupan los textos narrativos ya sea por su contenido o por su composición. La crónica y la novela son dos ejemplos claros de modelos de estructuración formal y temática en los que el escritor retrata, a partir de la realidad, en el primer caso, o de la ficción, en el segundo, la historia de una sociedad dada con la mayor autenticidad y verosimilitud de que sea capaz. Esto es así, toda vez que, como lo sostiene Martha Nussbaum en su obra El conocimiento del amor. Ensayos sobre filosofía y literatura $(2005,29)$, el sujeto hacedor, así como el destinatario de la obra literaria, encuentra en el texto escrito cuestionamientos justificados, concretos, así como proyecciones de la existencia humana. No en vano, la palabra es su herramienta. Si se escudriña en el origen etimológico del vocablo, se podrá entender su sentido. Literatura viene del latín "litteratūra" (Aguilar, 1976), que significa la actividad del "litterator", el hombre que maneja las "litte-rae", que no era más que el maestro de la expresión correcta del lenguaje latino, el artesano de las letras, el productor de historias, el letrado, en definitiva, el escritor.

Los textos narrativos son instrumentos que entrañan diferentes modos de comprensión, de representación, de resignificación y de explicación del mundo. Su elección y utilización no puede llevarse a cabo por el mero acopio de información atinente a la clase de autores, a los títulos de las obras, a los géneros literarios a los que se adscriben o a los temas que trabajan, su lectura debe pasar, sin desmeritar lo anterior, por la experiencia íntima y transformadora del lector. El cometido de esta manifestación artística que modela la palabra no es inducir al destinatario de la obra literaria al encuentro de una verdad oculta, única e insoslayable, sino el de propiciar, a través de la provocación y del encuentro de identidades, la interacción entre el escritor, el narrador, lo narrado y ese público que lee. Para Foucault la literatura es testimonio del mundo figurativo, entre las ideas plasmadas en el papel se puede “[...] formar una ligazón de representación, [...] y la representación es siempre perpendicular a ella misma: ella es, al mismo tiempo, indicación y aparecer; relación con un objeto y manifestación de sí." (1966, p. 79). En consecuencia, el lenguaje literario es un lenguaje creativo, que 
trasgrede. Es un espejo basado en una ética cuyo relato tiene consecuencias directas en la transformación de subjetividades. Por eso, una obra literaria es una herramienta que sirve para re-crear, para poner en movimiento y en funcionamiento ciertos discursos al interior de la sociedad $\mathrm{y}$, en ese sentido, es un retrato de análisis y de construcción de la identidad.

A partir de subgéneros como la crónica testimonial, la novela histórica, la novela realista, o la dramaturgia, por ejemplo, el escritor puede indagar en la memoria colectiva como una manera de recuperar, revisar, explicar o reescribir la historia. El autor Antonio Gómez López-Quiñones, habla de una "ansiedad representativa" en el oficio de escribir, porque ante los hechos violentos producto de los conflictos y de las guerras, el escritor recupera las experiencias para visibilizarlas, le da un espacio a las voces de quienes fueron obligados al silencio - obligados a escuchar una sola versión de los acontecimientos - y por ende, recobra la memoria perdida (2006, p. 217). No obstante, es imperioso aclarar que el escritor, en este tipo de literatura, interpreta las narraciones o los discursos de otros, nunca realiza una interpretación directa de la realidad o sobre la verdad, puesto que aquello que pretende contar ya ha ocurrido, gravita sobre hechos pretéritos, y por tanto su trabajo hermenéutico gira en torno a lo ya contado desde perspectivas diferentes. Él recoge los datos y los re-significa, porque para "[...] realizar o hacer realizable esta reinterpretación dinámica, se esfuerza por documentar no tanto lo ocurrido como lo ya narrado; es decir, lo inventado. Un hecho concreto da lugar a una invención lingüística, y ésta a otra ad infinitum hasta suplantar totalmente lo ocurrido con lo contado" (Spires, 2005, p. 81).

En ese trabajo de crear una obra que sirva de instrumento testimonial y construya civilidad, el escritor debe hacer uso de herramientas literarias que aporten verosimilitud al texto ficcional o no ficcional en este último caso se hace referencia a la crónica literaria-, tales como la polifonía o multiplicación de las voces. Aquí se trae de nuevo la teoría Bajtiana, pues la deconstrucción de la voz narrativa da lugar a una infinidad de versiones disímiles sobre los mismos hechos, lo cual permite dar cabida a la pluralidad y al reconocimiento de la otredad dentro de ese escenario de la búsqueda del perdón que entraña el posconflicto. Por tanto, será el lector, quien es destinatario y coautor de la obra, el que debe elegir la versión que más se ajuste a su propia interpretación y el contenido que le quiera dar al relato. $\mathrm{Y}$ es que "[...] al no ofrecer una visión única se pone de manifiesto una lectura en absoluto maniquea de la historia, evidenciando que la «realidad» es demasiado compleja como para que un solo narrador pueda darnos cabal cuenta de ella" (Albizu, 2009, p. 83).

Dice el escritor Juan Gabriel Vásquez que la lectura tiene como correlato directo al hechizo y ello, porque se lee "para ser hechizados, $\mathrm{y}$, en el hechizo, para vivir las vidas que no hemos podido vivir" (2009, p. 23). Pero como no hay lector sin escritor, Mario Vargas Llosa sostiene que es la rebeldía la causa de esa disposición innata a narrar, pues "quien se abandona a la elucubración de vidas distintas a aquella que vive en la realidad, manifiesta de manera indirecta su rechazo y crítica de la vida tal como es, del 
mundo real, y su deseo de sustituirlos por aquellos que fabrica con su imaginación y sus deseos" (2015, p. 15).

Es en este sentido que la obra literaria debe ser entendida y aprehendida como un modo de explorar la realidad. No con la mirada de lo que realmente ocurrió, porque no implica una reproducción novelada de los hechos verificables en el mundo empírico, por el contrario, es una mirada respecto de hechos posibles. La literatura, la buena, sin importar el género en la que se enmarque, se mueve en el lindero reducido de lo imaginado y de lo real. Es ahí donde el escritor se convierte en mago del lenguaje desentrañando un pedacito de humanidad. "Contar algo" es su objetivo sin que se le noten el artificio o los trucos, es un contar que supera la imposibilidad que ha tenido, tiene y tendrá el ser humano de conocer la historia tal cual como ocurrió, porque toda historia, a través de las diferentes épocas, siempre ha sido una versión, y lo único que puede hacer el escritor ficcional o no, es retratar o recrear desde su propia mirada lo acontecido. Un buen contador de historias es un creador de mundos, de realidades alternativas simuladas o ciertas. Es en últimas, un historiador contrafactual. Pero como cualquier mundo, éste debe dar la impresión de totalidad y universalidad, y esa sensación sólo se alcanza a partir de tres características básicas que han de gravitar en el quehacer del escritor: la observación, la identificación y la inmersión. Sin embargo, ese efecto de completud que debe tener la obra $-y$ contra todo pronóstico - se alcanza con la concreción en el uso de las palabras: los personajes, sus vidas, lo que los rodea, deben ser circunstancias singulares, en un espacio definido, en un tiempo determinado y a partir de acciones específicas que le permitan al lector ampliar lo narrado mediante su propia experiencia respecto a una vivencia semejante. Sólo así podrá sumar a lo visto o vivido por él en el plano de lo real, sus percepciones sobre aquello que se le cuenta.

Como lo señala Oscar Tacca en Las voces de la novela (1973, p. 13), el escritor, como el músico, tiene que aprender a tocar los instrumentos con los que crea: la materia prima, que no es más que el ser humano, y las palabras. El constructor de narraciones hace música con los hechos y con el lenguaje, ordenando en su propio pentagrama las palabras escogidas, permitiendo así que lleguen de una manera armónica y concreta al oído del lector. Es ese el pacto de confianza que el autor suscribe con el lector. Para que él se atreva a leer hasta llegar al último párrafo de la historia debe saber "quién le cuenta y cómo se lo cuenta", de lo contrario perderá el interés por no poder fiarse de quien le abrió las puertas a ese territorio alterno que quiere conquistar. El filósofo trata de explicar el mundo a través del conocimiento, el escritor lo hace a través de versionar la historia, pero en ese trabajo de recreación, la novela o la crónica se constituyen en un puente que une el relato y a quien lo narra con el ser ético de quien recibe, del lector, pues ella comprende y alberga campos de información que van más allá del propio contexto literario. Ambas, permiten repensar aspectos como el poder, la sociedad, la cultura, la identidad, la subjetividad, las costumbres, entre otras; entonces, y siguiendo al nobel de literatura Vargas Llosa, la verdad que se quiere trasmitir depende de la capacidad de persuasión que el texto ejerza "[...] de la fuerza comunicativa de su fantasía, de la habilidad de su magia. Toda 
buena novela dice la verdad y toda mala novela miente" (2002, p. 12),

Lo anterior da como resultado, dentro de la literatura testimonial, sea ficcional o no, la reconfiguración del perdón y la reconciliación en escenarios de posconflicto como el que pretende alcanzar Colombia. Al narrar lo sucedido desde diferentes visiones, tanto de los vencidos como de los vencedores, de las víctimas y de los verdugos, se permite el reconocimiento de las faltas propias y ajenas, de sus limitaciones y de la imposibilidad de deshacer lo hecho, para, después, comprender en el otro su actuar; la obra se convierte, de esta manera, en una herramienta estética de toma de consciencia de la tragedia de un pueblo a través de las vivencias de los personajes, y permite la oportunidad de reconstruir un futuro en el que, a partir del recuerdo, se combata la irreversibilidad del tiempo.

\section{LA LiterATURA COMO "DEPÓSITO" DE UNA MEMORIA TESTIMONIAL}

\section{La literatura es una noticia que siempre es noticia}

Ezra Pound

La literatura es un espacio plural de mundos que no por sus mayores posibilidades interpretativas deja de tener reglas, las cuales delimitan cada tipo de narración y, en este sentido, cada tipo de género. El debate por los géneros literarios es añejo y aún sigue vigente; para hacer referencia a esta historia de los géneros debe decirse que en el principio era la poesía, es decir, que antes se entendía como poesía al género total de lo que en el presente denominamos literatura
(Aguiar, 1972), luego, el significado de poesía transitaría hasta convertirse en literatura en la segunda mitad del siglo xvin, en Europa. Expone Aguiar que "La evolución de la literatura sigue, $y$, hacia el fin del tercer cuarto del siglo xvin, literatura pasa a significar el conjunto de las obras literarias de un país [...]" (1972, p. 12), y termina el autor señalando que "al concluir la penúltima década del siglo xvıI, la palabra literatura [...] se va hacia la noción de creación estética, como específica categoría intelectual [...]" (p. 12) Luego esa literatura se dividirá también por géneros, dada la necesidad humana por clasificar.

Esta división entre los géneros ha sido problemática en razón a la pregunta ¿qué es y qué no es literatura? Hay que decir que desde la antigüedad hasta la contemporaneidad, el criterio sobre la sustancia de la literatura y la clasificación de la misma ha distado dependiendo de la valoración de unas y otras escuelas de pensamiento, pero, en general, en el transcurso histórico se ha hecho un recorrido desde una visión cerrada y limitante hasta una omnicomprensión de lo que es la literatura. Esto permite, no sólo salir de los géneros tradicionales - novela, cuento, poesía, dramaturgia-, sino, además, propugnar por la importancia de la hoy citada literatura liminal; es decir, aquella que escapa a la limitación del canon tradicional y, por tal, problematiza las preguntas básicas del lector, del crítico y del académico. Explica Aguiar (1972) que esta ruptura con los géneros tradicionales tuvo como una de las iniciales manifestaciones a la alianza novela-realismo: "la gran época del realismo llegó con el desarrollo de la novela moderna en los siglos xviı y xviıI" (Chillón, 1999, p. 89). Al respecto, concuerda 
Aguiar en que estos géneros híbridos: "la novela realista de ficción, la prosa literaria testimonial, la narrativa científica y la escritura periodística son facetas distintas pero conexas de un mismo fenómeno cultural [...]: la nueva sensibilidad realista característica de la época moderna" (Aguiar, 1972, p. 17). Es pues un fenómeno no solo literario o académico sino cultural, una necesidad de desbordar el límite tan fieramente establecido por las fuerzas de poder inscritas en todas las instituciones; a la dominación y autoritarismo no podía escapar la institución literaria.

Es por ello que la mezcla entre géneros hizo problemática la categorización de lo literario y de lo no literario. Pero las literaturas del límite o híbridas no solo aportaron un problema a la resolución de cuestionamientos tradicionales, sino que también dieron vida a nuevas formas de narrar el mundo que se adaptan a las necesidades siempre cambiantes pero ineludibles del humano por recrear sucesos, describir escenarios, explicar conductas; en suma, hacer y escuchar historias. Dentro de esta transición de los géneros preestablecidos de la literatura, también ocurrió una simbiosis entre lo que era literario propiamente dicho, es decir, novela y ensayo, poesía y relato, novela y relato, entre otros; y lo que en su momento fue extraliterario por pertenecer a otras áreas del conocimiento: la psicología, el derecho, la sociología, el periodismo. Es por ello que empezaron a surgir narraciones interdisciplinares que retaron la visión de lectores y académicos y además lanzaron nuevas preguntas de discordia ¿qué es la realidad y qué es la ficción?, ¿cuáles son los límites?

Estas preguntas se hicieron necesarias pues desde la antigua Grecia, a los poetas, a los literatos, se les tildó de sujetos dedicados a la mímesis, al invento, de manera que se concibe tradicionalmente a la literatura como una narración ficticia que no tiene relación con lo real. Pues bien, si esta es la concepción generalizada, ¿cómo entender que ciencias sociales y humanas como el derecho, el periodismo, la psicología, entre otras, se fundan con la literatura?, ¿cómo puede saber el lector de un periódico, por ejemplo, que la noticia que lee sí es real, cuando tiene el tono estético, metafórico y personalista de lo literario? Pues bien, estas fueron las primeras preguntas que se realizaron los periodistas en estricto sentido cuando vieron nacer el género del periodismo literario. Muchos apelativos despectivos proliferaron para este tipo de periodismo, pero su fuerza fue fundamental para acercar de nuevo el hecho social a los ciudadanos; hecho social perdido en un discurso informativo, objetivo y frío propio de la noticia. A pesar de las críticas, autores como Puerta consideran que el periodismo literario no desvirtúa su condición de relator de la verdad, en tanto: "aunque utilice diversas técnicas y distintos recursos, no inventa nada, porque en él está presente el compromiso de informar, y es narrativo porque busca contar historias, hacerlas entretenidas para los lectores y con tal grado de profundidad que se conviertan en un reflejo de su época" (2009, p. 67) 1legó pues para quedarse el periodismo literario, fruto del cual nació lo que se denominó como crónica, buscando conectar al lector con la realidad, una que había desatendido el alejamiento del periodismo tradicional, un periodismo positivista, empirista, científico-cuantitativo. La literatura, en unión con el antiguo periodismo, gestó un árbol híbrido que no por estético e intimista dejó de hacerle frente a la verdad. 
Entonces, la crónica tiene nacimiento en esta unión interdisciplinar, pero para poder explicar qué se entiende por crónica, debe exponerse primero, tal y como lo afirma Chillón (1999), que la unión entre literatura y periodismo se conoce desde mucho antes de la contemporaneidad, aunque ahora haya cobrado una particular importancia. Explica el autor que su nacimiento se rastrea desde la obra que el escritor Daniel Defoe publicó en 1722, Diarios del año de la peste, en la cual el periodista y novelista hacía un retrato de los horrores de la peste bubónica pero sin acudir al uso informativo del lenguaje sino, en cambio, mediante una descripción de hechos reales pero acercada a la prosa novelada. Esta nueva fórmula de darle un rostro avanzó hasta convertirse en una pluralidad de géneros que actualmente se agrupan en el margen de la intersección literatura y periodismo. Espacio híbrido en el cual además de la literatura y el periodismo se mezclan géneros del periodismo y las distintas formas de lo literario; a este multigénero se le ha dado el nombre de crónica.

Aun cuando para la mayoría de los autores la crónica no es un género, sino una multiplicidad de géneros reunidos y por tal, su denominación es escurridiza, puede aventurarse una explicación con fines de comprensión inicial. Para ello se acepta, como lo dice Carlos Mario Correa (2011), que "El concepto de crónica se origina en el vocablo latino chronicus - que a su vez se deriva del griego kronos, tiempo [...], es decir, libros compuestos por uno o más relatos que siguen el orden del tiempo-" (p. 34) Es pues, en inicio, una narración temporal en su sentido más tradicional, lo cual da la idea de que lo contado tiene relación con un tiempo y que el relato responde a una determinada cronología.
Otro autor que intenta definir los linderos de la crónica es Juan Villoro, para quien la crónica trabaja los sucesos en el tiempo, pero al igual que la novela, no puede liberarse de los hechos sino hacerlos verosímiles a través de un simulacro, recuperarlos del pasado como si volvieran a suceder con la misma intensidad a los ojos del que, directa o indirectamente, los vivió. Si bien, aquel género da cuenta de testimonios reales y la novela relata la vida de personajes de carne y hueso imaginarios, tanto el cronista como el novelista trabajan con préstamos, "por más que se sumerjan en el entorno, practican un artificio: transmiten una verdad ajena. La ética de la indagación se basa en reconocer la dificultad de ejercerla. El intento de darles voz a los demás es un ejercicio de aproximaciones" (2006). Para Villoro es también una narración que responde a lo cronológico.

En consecuencia, la crónica es un conjunto de géneros diversos que por razones de delimitación se sitúa en una sola denominación y sus postulados son contrarios a los del tradicional periodismo informativo, en tanto éste último responde a una concepción de la información en relación con la práctica objetiva de los métodos de conocimiento objetivista. Es decir, para los periodistas tradicionales la noticia es un recuento objetivo de un hecho, en cambio para el cronista esa verdad nace de una mirada particular de la que no escapa el escritor y es por ello que, aunque se apoya en datos verdaderos, o verificables en el mundo empírico, la forma en que relata ese suceso es cercana a lo subjetivo y busca generar su mirada particular del mundo de ese hecho noticioso. Por ello, Villanueva Chang, se aventura a defender la crónica diciendo que: "para un lector una crónica ya 
no es tanto un modo literario de 'enterarse' de los hechos, sino también una forma de «conocer» el mundo. La crónica se ha vuelto una forma de conocimiento. Un cronista ya no es sólo un escritor de la información. Se necesitaba una definición más ética. Ahora su tarea parece ser contar una historia de verdad y evidenciar los síntomas de su época. Se trata de convertir el dato en conocimiento" (Villanueva Chang, 2006, p. 57).

El nacimiento de la crónica tiene una relación intrínseca con la ruptura de la visión del racionalismo que excluía al sujeto de la actividad del conocimiento, cuando se cambia la concepción de una verdad única verificable e inmutable, el ser humano entra en una época de complejidad en la cual se entiende que la verdad tiene formas plurales o, que no es correcto hablar de la verdad, sino de pretensiones de validez. Por ello, cuando un hecho ocurre no es única la mirada que puede dársele sino que tendrá tantas miradas como observadores lo presencien. Para Carlos Mario Correa (2011, p. 45) la crónica responde a esas múltiples pretensiones de validez con que se pueden interpretar los sucesos del mundo, aunque las circunstancias verificables lo seguirán siendo siempre en el mundo de los fenómenos, la recepción que el sujeto tiene del hecho en cuestión varía dependiendo de la realidad en la cual se haya formado. Por ello Carlos Correa afirma (citando a Rodríguez, 2010, p. 30) que la crónica “deambula por todos los rumbos y capta los variados matices de lo humano [...]". Es necesaria la crónica en el presente si se tiene en cuenta su valor como narrativa, como vínculo de lo humano con los sucesos que configuran su historia. En este sentido, Hoyos (2007, citando a Martínez, 1997) explica que "Las palabras escritas en los diarios no son una mera rendición de cuentas de lo que sucede en la realidad. Son mucho más. Son la confirmación de que todo cuanto hemos visto sucedió realmente, y sucedió con un lujo de detalles que nuestros sentidos fueron incapaces de abarcar".

La crónica sirve de vínculo entre las distintas subjetividades y las esferas de lo común, permite redescubrir el suceso y darle una nueva significación. En este punto, la crónica como unión de la literatura y el periodismo se constituye no sólo en un valor significativo para cada una de estas áreas académicas sino que también arroja luces sobre algunas otras áreas como lo son las distintas ciencias sociales y la posibilidad de relación del sujeto con su proceso histórico. Este cercamiento del sujeto a la narración permite configurar la realidad y al mismo sujeto, dado que si los fenómenos de la realidad pueden mirarse con otros ojos, la concepción inicial de dicho fenómeno puede recrearse de manera distinta en el cognoscente. La crónica en particular permite este acercamiento del ser humano con la realidad dado su componente cronológico, es su narración, inscrita en un tiempo específico, la que da cuenta de una narración por espacios de tiempo o escenas y "la narración escena por escena tiene el privilegio de contarnos las historias de un modo muy parecido al que los hombres usamos a diario para ver la realidad" (Hoyos, 2007, p. 25).

La crónica interrelaciona los diferentes actores sociales, con la finalidad de rehacer las circunstancias ocurridas; así lo expone Juan José Hoyos cuando indica que "podemos no comprender plenamente los sistemas de pensamiento de otra cultura, pero tenemos mucha menos dificultad para entender un 
relato que procede de otra cultura [...] un relato siempre se puede traducir sin menoscabo esencial" (Hoyos, 2007, p. 33). La humanidad no puede escapar a lo narrativo, en la esencia de los humanos se encuentra inscrita la necesidad de recrear sucesos a través de historias. Del arte de narrar. Por ello el relato propio de la crónica es un espacio para la comunicación plural. También indica Hoyos (2007), refiriéndose a lo teorizado por Weinrich, que: "se ha comprobado en diversas disciplinas de las ciencias sociales y humanas que la narración ofrece las mejores condiciones a la memoria cultural de una civilización" (p. 38). De manera que la crónica propicia la posibilidad de reconocimiento, memoria y reconstrucción de la realidad que requiere la convivencia social. El proceso narrativo de los hechos que ocurrieron en un momento histórico, al ser leído por los actores del mismo, puede ser visto de manera distinta a como la memoria, escasa y falible, del observador lo vio por primera vez.

Es por ello que la crónica desarrolla un proceso al tiempo colectivo e individual. Colectivo en la medida en que la época retratada corresponde a todos los humanos en un momento dado; y por lo cual, el lector se siente identificado con ese todo orgánico de contenido cronológico propuesto por el texto. También se trata de un desarrollo individual ya que permite poner en juego cualidades o circunstancias conscientes e inconscientes del sujeto: "De modo tal que se pueda identificar los rasgos trasversales o comunes entre distintos participantes, pero también rescatar las diferencias, lo genuino de cada biografía, de modo tal que en una misma narrativa se puedan hacer visibles y audibles en un mismo nivel de legitimidad las narraciones convergentes y divergentes, o la polifonía de voces que reflejan la dimensión problemática del conocimiento" (Gergen 2008, pp. 165-166). La crónica, como un espacio polifónico, se constituye en un prisma de posibilidades para abordar la interpretación de lo narrado y de los narratorios, mostrando el problema abordado mediante una figura cubista que evita apelar a lo reduccionista o a la perspectiva unidimensional.

\section{LA LiterATURA COMO ALIADA DEL PERDÓN EN EL CONFLICTO ARMADO INTERNO COLOMBIANO}

Teniendo claro el papel de la crónica como multigénero híbrido nacido del periodismo literario, que también se erige como puente para llevar los fenómenos de vuelta a los actores que en su momento lo vivieron, cabe la pregunta por el papel de esta crónica para el acontecer histórico y político de una nación. Es en este punto donde el presente artículo, y la investigación de la cual él se deriva, considera la crónica como narración literaria, como un elemento determinante y aliado para el perdón que debe obrar en los ciudadanos después de que han vivido las atrocidades de la guerra.

Por ello puede afirmarse que el género crónica es una manifestación de narratividad que permite reconfigurar subjetividades que tiendan hacia la obtención del perdón, a través de la posibilidad de otras miradas de los actores del conflicto respecto del hecho acecido. Es pues un medio literario idóneo para buscar la configuración del perdón dentro de las mentalidades de ciudadanos que durante décadas, directa o indirectamente, han estado inmersos en guerras tan 
crueles como el conflicto interno armado en Colombia.

Pero antes de hablar de las circunstancias que propician otras miradas tendientes a los procesos de perdón es fundamental preguntarse si éste es una condición necesaria en contextos posacuerdo o es apenas un componente subjetivo de la moralidad. Pues bien, tradicionalmente se ha entendido que un orden social fracturado requiere memoria, verdad, justicia, reparación y no repetición. Sin embargo, el perdón se constituye en un elemento fundamental para el desarrollo de lo anteriormente descrito, ya que al consolidar la memoria del hecho se requiere luego el perdón como la aceptación del hecho inevitable, no para fomentar procesos de civilidad entre bandos, sino para permitir que el sujeto pueda dejar atrás lo ocurrido y tomar posición hacia el futuro. En palabras de Villa (2016) “el perdón debe entenderse como "un proceso en el cual la víctima abandona este lugar, para convertirse en actor y sujeto de su propia vida, en sobreviviente y testigo, en ciudadana, capaz de comprometerse con la transformación de su realidad personal y social" (p. 149).

Así como el perdón está relacionado con la memoria, lo está con la verdad, la justicia y la reparación que son presupuestos para hacer frente a lo ocurrido y poder reconstruir. Así mismo, el perdón posibilita la no repetición en tanto supone la comprensión global de un hecho y el empoderamiento del sujeto de una visión global del fenómeno y permite el alejamiento imprescindible para comprender las causas, los efectos y tomar conciencia. El perdón es pues el elemento que atraviesa verdad, justicia, reparación y no repetición, porque empodera al sujeto de una nueva perspectiva, antes oscurecida por el dolor, la incomprensión del fenómeno y la ausencia de reconocimiento.

Esta posición transversal sobre el perdón en los procesos posacuerdo se describe en Garrido (2008) cuando explica que aunque, tradicionalmente, "la definición del perdón ha estado inmersa en un continuo debate entre las perspectivas que consideran que sólo podría remitirse al ámbito individual y moral, otras que lo asimilan a procesos jurídicos sujetos a legitimación social y otros que le dan significación sólo con base en un sistema de valores religioso" (p. 127) Éste es: "un mecanismo micropolítico poderoso para la resolución del problema de la convivencia en procesos de reconciliación; micropolítico, tanto porque abarca procesos que se dan por fuera de las instituciones formales, como por estar compuesto por microfundamentos como las emociones, las preferencias, las motivaciones" (p. 161). La autora estudia los procesos posacuerdo de Argentina, El Salvador y Sudáfrica e indica que los denominados procesos reconciliatorios subvaloraron la importancia del perdón real como humanización del otro y de sí mismo y esto afectó directamente los procesos de no repetición.

La investigadora concluyó que, en estos casos, el perdón fue una categoría legal que no llevó a reales procesos de transformación subjetiva. Además, estableció que el perdón es muy importante en los procesos posacuerdo y requiere el cumplimiento de un proceso desde el ámbito individual, colectivo e institucional formal, que va desde el reconocimiento del otro y la toma de conciencia, hasta la construcción de herramientas culturales y mecanismos estatales que 
posibiliten la solidez de los acuerdos. Así las cosas, concluye frente al perdón que: “Los procesos que se lleven a cabo en el ámbito de las instituciones formales son imprescindibles, de forma que el perdón no debe ser sólo adjudicado a la esfera privada individual, sino que puede ser abordado desde la responsabilidad política de actores formales" (Garrido, 2008, p. 160). Es claro que el perdón es una condición que debe ser tenida en cuenta para hablar de consolidación de posacuerdo en miras a un periodo real de posconflicto, como es el caso de Colombia.

El perdón, como ya se explicó, tiene una relación inicial con la memoria y con la necesidad de reconocimiento que tiene la víctima. Es decir, con ser escuchada, con la posibilidad de recordar el hecho que fracturó su vida y volver a sentirse identificada con otros. Si se pudiera definir un momento en la historia en que la rutinización de la guerra y del olvido dio paso a la memoria colectiva de los hechos violentos, tendría que pensarse en las postrimerías del holocausto nazi (Huyssen, 2002, p. 21). A partir de ese suceso, la obsesión por el recuerdo empezó a ser una constante en occidente. En las diferentes latitudes, los auges memoriales convirtieron a la literatura en un instrumento en el cual depositar la memoria testimonial, ya que, de alguna manera, la narrativa sirvió de eco a la voz de los excluidos y de las subalternidades acalladas por las élites de poder, $y$, muchas veces, por los victimarios. Entonces, el carácter vital del texto literario, en especial del texto cronical, implica "la expresión de un sentimiento popular que ha sido acallado, cubierto por las informaciones oficiales" (Theodosíadis, 1996, p. 18) durante mucho tiempo y que supone una reivindicación de quienes han permanecido ocultos tras el silencio y la invisibilidad como víctimas de los antagonismos sociales.

En ese escenario es en donde aparecen las narrativas del conflicto y, con ellas, las narrativas del perdón. En el discurso de la guerra, y en especial en el discurso del conflicto armado surgido en Colombia desde mediados del siglo $\mathrm{xx}$, las víctimas eran sólo un costo a pagar, y como si fueran objetos, sólo se les tenía en cuenta para engrosar los balances de pérdidas de los enfrentamientos. Las narrativas del conflicto en Colombia son múltiples, entendiendo que la literatura es una creación que parte, ineludiblemente, de su contexto social. Sin embargo, la crónica periodística ha permitido narrar desde una óptica plural los hechos, las visiones de los diferentes actores y constituirse en escenario para iniciar procesos de reconocimiento que lleguen a una final reconciliación mediado por el perdón.

El tipo de crónicas que pueden denominase como narrativas del perdón son aquellas que han retratado justamente la violencia y las posiciones de los diversos actores. Para Carlos Mario Correa, "En un país como Colombia, con más de cinco décadas de conflicto armado [...] la violencia y sus manifestaciones es un asunto que les es difícil soslayar a los cronistas" (Correa, 2017, p. 57). Para el autor, este tipo de relato se ha denominado como crónica roja, crónica judicial o de la violencia y tiene repercusiones en la forma de afrontar las subjetividades dentro de un sociedad. Tanto es así que la denomina como "el altavoz de la víctima", aduciendo que: "aunque los medios de comunicación hegemónicos informan sobre la violencia, ésta no suele trascender más allá del dato 
noticioso de una imagen anónima o de una víctima desconsolada por unos segundos frete a la cámara" (Correa, 2017, p. 58).

Este autor explica cómo la crónica de la violencia en Colombia es una narrativa que sobrepasa el acontecimiento singular para convertirse en memoria colectiva. Se logra así que la víctima se sienta comprendida por una colectividad, pero de manera más importante, transforma la historia, que en la noticia es apenas un hecho aislado, en una narración con trama, personajes, diversos ángulos y enfoques, lo cual permite el distanciamiento necesario para que la víctima y el victimario recreen las condiciones y circunstancias que llevan al hecho dañino y puedan perdonar, volver a reconstruir sobe lo dado.

Correa asegura que una de las cronistas imprescindibles en Colombia es Patricia Nieto, quien logra, con sus relatos, romper la "mudez de las víctimas que ha traducido en amnesia e impunidad" (Correa, 2017, p. 66). Se centra en textos importantes como Llanto en el Paraíso. Crónicas de la guerra en Colombia (2009), o Los escogidos, textos que rescatan del olvido historias de la violencia del país y que les dan voz a las víctimas del conflicto. Existen autores igualmente imprescindibles en este tema, algunos de ellos son Arturo Alape quien con su texto El Bogotazo, memorias del olvido intenta hacer ver los hechos que originaron la violencia en Colombia y las circunstancias que se desencadenaron con la muerte de Jorge Eliecer Gaitán; Alfredo Molano, cronista inigualable de la violencia y de los actores del conflicto; Olga Behar, Germán Castro Caicedo, Alberto Salcedo Ramos, entre otros.

Este aporte es importante cuando la víctima se hace visible, y entonces el dolor y la memoria individual se transforman a través de la narración y de la palabra, en un dolor y una memoria colectiva que permite la desvirtualización del enemigo. Esto posibilita la transformación de la sociedad mediante el posicionamiento de esa violencia en una escala de personaje, en donde a partir de un diálogo entre contextos, procesos y subjetividades se logra dotar de sentido a una versión de los hechos ante el público destinatario del relato.

En este orden de ideas, se debe hablar del texto narrativo como espejo, porque es a través de sus líneas que se establece un complejo juego de voces compuesto por las historias de quienes, dentro de esa dinámica de confrontación constante, han ocupado el puesto de sujetos golpeados o se han instalado en una posición dominante como actores irregulares porque reordenaron el espacio nacional en función de sus propia escala de valores e imaginarios distribuyéndose así, en los mapas de la guerra, el poder de decidir sobre la vida y sobre la muerte de los pobladores.

La literatura, en este caso la crónica de sucesos, roja o judicial, debe entenderse como el registro de un escenario de conflicto armado interno que integra los relatos personales y colectivos de quienes habitan la gran mayoría de la geografía colombiana. También es una re-creación del salto de una memoria individual al momento social de la memoria, con el objeto de alcanzar una verdad que cree fronteras éticas, personales, sociales, políticas y, en ese camino, lazos de entendimiento de la otredad, de lo distinto, del contrario. Lazos de perdón, que de manera definitiva sean el llamado a un "nunca más".

La crónica es un ejercicio en el que el autor escribe para un lector ideal, y a su vez 
el lector, el definitivo, el de carne y hueso, reescribe lo narrado cuando lo lee, y es ahí cuando hay una trashumancia de la obra. El lector se transforma no en el autor, sino en otro autor, convirtiendo la lectura en la escritura de un nuevo libro. Recupera el código y lo transforma en un mensaje absolutamente personal e intransferible, un mensaje que a partir de la magia de la contemplación refleja la esencia de la voz que lo ha creado a través de la pluma, o lo convierte, según sus experiencias de contexto, en un nuevo relato que explique lo vivido por él y alivie el dolor, la rabia, la impotencia o la incertidumbre. Hablar de narrativas del conflicto y de narrativas del perdón es hablar de un ejercicio de catarsis, de resistencia, de búsqueda. Es hablar de una construcción conjunta entre el escritor y el destinatario, porque ambos, frente al mismo texto y frente a los mismos hechos, reflejan, reconstruyen y resignifican la historia del ser humano. Por eso debe entenderse a la escritura como un lenitivo contra la oscuridad, así lo señala la escritora Rosa Montero cuando afirma que a través de la narración "el escritor puede atrapar sus pensamientos, sus conocimientos, sus emociones; puede fijarlos en un papel como quien arroja una botella al mar del tiempo" (2016, p. 188).

Mario Vargas Llosa sostiene que "una sociedad sin literatura o en la que la literatura ha sido relegada, como ciertos vicios inconfesables, a los márgenes de la vida social, [...] está condenada a barbarizarse espiritualmente y a comprometer su libertad" (2015, p. 11). Por eso, en este proceso de construcción de paz en el que está inmersa Colombia, si no se quiere alcanzar un fracaso que devuelva al pueblo a una guerra aún mayor donde la invisibilidad del conflicto sea un grito a voces pero sordo, es indispensable que las crónicas sean utilizadas como insumo de cambio social, empoderando a todos los colombianos de un discurso inclusivo, a través de la explicación del concepto de perdón, que involucre el conocimiento de la verdad a partir de un consenso dialógico entre víctima y victimario.

El constructo del perdón sólo puede partir del relato de los hechos. De entender y dar a entender que los verdugos hacen parte de un mismo engranaje social, cultural y político, y que a veces sus actos de atrocidad se explican por la misma ineptitud de un aparato estatal que ha dejado desprotegido al poblador dejla opción, la única, de sobrevivir como pueda.

Colombia está en un momento en que la palabra está ocupando lentamente el puesto del silencio. El puesto de un olvido que hizo, durante mucho tiempo, que "[...] las formas de terminación de las guerras dejaran sin resolución el contencioso de la memoria" (Suárez, 2011, p. 280). Hasta hace muy poco las víctimas optaban por la elipsis dentro de su historia de vida como forma de sobrellevar el duelo, el desarraigo, la perdida, la indignidad en que otros los sumieron, pero también usaron una actitud muda como estrategia para mantenerse vivos o resucitar sin estar muertos, porque siempre, en todas las épocas y en todos los escenarios, la palabra ha entrañado riesgos. La palabra reta, intimida, descubre, hace dudar, y la duda es el peor enemigo de los poderosos, por eso la han restringido a través de los siglos. Se censura al orador, se lapida, se quema, se mata, se borran las letras como si no se hubieran estampado en el papel. En estos años de conflicto armado hubo 
una carencia de alguien con actitud de escucha y por eso se han producido pérdidas testimoniales irreparables para el esclarecimiento social y político de las atrocidades en el país, que hubiesen podido conllevar a la reinvención de la vida personal y colectiva convirtiéndose en instrumentos potenciales de transformación pedagógica, ética y jurídica. El escritor, al trasladar del escenario íntimo a lo público las historias que exigen ser narradas, tiene una finalidad declarativa. Un objetivo amplificador de la voz de quienes han estado subordinados por el poder, potenciando así a los grupos sociales que "emergen en movimientos de liberación y recomponen, desde una postura privada (la del testigo), una posición de 'conjunto' o de clase estructurada en torno a intereses ideológicos o situaciones coyunturales de reivindicación de sus derechos" (García, 2003, p. 24).

Por eso, el texto literario debe desafiar la capacidad de narrar lo vivido enfrentando el imperativo de contar, cumpliendo un papel restaurador y dignificante que de manera proyectiva imponga como obligación social, en cabeza de todos los actores, la reconstrucción de la convivencia y la reconfiguración del sistema democrático, pues es a partir de la diferencia que se construye la identidad. Ese es el reto de la literatura, "[...] escribir hasta que la eternidad quepa en un instante" (Cortázar, 2013, p. 9), entregarle al lector no sólo una etnografía del dolor sino un documento con vocación pedagógica que permita comprender el dolor. En el marco de la violencia, el dolor no compete sólo a la parte de la sociedad que directamente se vio y se ve afectada por el conflicto armado, sino que su padecimiento "en ese otro que pude y puedo ser yo" tiene que superar la rutinización de lo cotidiano, y volcar a todo un pueblo en la asunción de unas narrativas de reconciliación que permitan una alternativa al fuego cruzado, y se conviertan en un manifiesto por la paz, por la reparación integral y por la convivencia, y recreen los elementos necesarios de un perdón a partir del cual se explique la construcción de sujeto como herramienta de reflexión que desvirtúe por fin la dicotomía entre el agresor y el agredido.

Marcel Proust resume de manera excepcional el cometido de la literatura cuando en su obra En busca del tiempo perdido señala que "[...] la verdadera vida, la vida al fin descubierta e iluminada, la única vida por consiguiente realmente vívida, es la literatura: ésa que, en un sentido, habita a cada instante en todos los hombres tanto como en el artista. [...] Solamente por el arte podemos salir de nosotros, saber lo que ve otro de ese universo que no es el mismo que el nuestro, y cuyos paisajes nos habrían permanecido tan desconocidos como los que puede haber en la luna" (Proust, 1993, p. 192).

\section{Conclusiones}

¿Por qué acudir a la literatura para recrear la configuración del perdón en el conflicto armado interno colombiano? Inicialmente porque la literatura es una fuente de información sociocultural en permanente recreación, que se define y expande a partir de la relación intersubjetiva de quien escribe y quien lee en un acto perdurable que se constituye en fuente de vínculos transmisibles entre sujetos a través del tiempo y el espacio. Con ello, la literatura hace posible la formación del sujeto político, de la acción política, esto es, de la comprensión 
del contexto histórico, social y cultural en el cual se alcanza una convicción propia frente a una dimensión de la realidad. Para nuestro caso, del perdón, y en lo posible, de su obligatoriedad, al acometer el asumir y cumplir deberes en beneficio del bienestar colectivo; de identificar y emprender responsabilidades desde la debida exigencia de derechos para sí y para el otro, como de acatar la realización de los deberes, todo ello, en un contexto histórico y social particular definido por el final del conflicto armado interno a través del perdón.

La literatura define identidades e invita a identificar, posiciona en un tiempo y un espacio, nomina acontecimientos e involucra de forma afectiva y racional con el propósito de movilizar acciones en el lector. La literatura es una posibilidad de asumir la realidad, dotarla de sentido y ampliarla desde la vivencia de quien la padeció, dando lugar a asumir lo vivido por quien lo sintió, pero sin limitar la posibilidad de recrearlo.

La literatura está enriquecida con la diversidad del lenguaje y con las formas de transmitirlo. En la crónica se supera la literalidad de las intensiones objetivas dando lugar a la subjetividad y a la capacidad de relatar desde una óptica que, más que verdadera, busca ser válida, asumida desde la pluralidad, para dotar de nuevos significados y rehacer las circunstancias acaecidas entre sujetos en un momento específico. Es en ese orden que la crónica como género literario propicia la posibilidad de reconocimiento, memoria y reconstrucción de la realidad que requiere la convivencia social, y donde la recurrente apreciación de los hechos por nuevos actores que los leen puede llevar a proporcionar nuevas cargas axiológicas. Por ello se reitera que el género crónica es una manifestación de narratividad ineludible que permite reconfigurar subjetividades que tiendan hacia la obtención del perdón, a través de la posibilidad de otras miradas de los actores del conflicto respecto del hecho acecido. La literatura se reafirma como el registro de un escenario de conflicto armado interno que integra los relatos personales y colectivos, pero también es una recreación del salto de una memoria individual al momento social de la memoria, con el objeto de alcanzar una verdad que cree fronteras éticas, personales, sociales, políticas y, en ese camino, lazos de entendimiento de la otredad, de lo distinto, del contrario. Como se mencionó, lazos de perdón, que de manera definitiva sean el canto a un "nunca más".

\section{ReFERENCIAS}

Aguiar, E. y Silva, V. M. (1976). La teoría de la literatura. Madrid: Biblioteca Románica Hispánica. Gredos.

Amar-Rodríguez, V. (2016). Leer la vida. Una investigación desde la perspectiva narrativa. Revista Latinoamericana de Ciencias Sociales, Niñez y Juventud, 14 (2), 975-986.

Alizu, C. (2009). Literatura y memoria: Amalgama discursiva y reflexión metaliteraria en Los girasoles ciegos de Alberto Méndez: triunfo del discurso metaliterario sobre la derrota histórica. Revue Suisse des Littératures Romanes,56, 67-83.

Álvarez, N. (2011). La polifonía bajtiana en la novela Del amor y otros demonios. Revista de Lenguas Modernas, 14, 147-164. Bajtín, M. (1995). Estética de la creación verbal. México: Siglo xxI. 
Canelles, I. (1999). La construcción del personaje literario. Madrid: Fuentetaja.

Chillón, A. (1999). Literatura y Periodismo. Una tradición de relaciones promiscuas. Barcelona, España: Universidad Autónoma de Barcelona.

Correa, C. M. (2011). La crónica reina sin corona. Periodismo y literatura: fecundaciones mutuas. Medellín, Colombia: Fondo Editorial Eafit.

Cook, T. D. y Reichardt, CH. S. (1986). Métodos cualitativos en investigación educativa. Madrid: Morata.

Cortázar, J. (2013). Clases de literatura. Berkeley, 1980. Bogotá, Colombia: Alfaguara.

Correa Soto, C. (2017). Narradores del Caos. Las Apuestas de la Crónica Latinoamericana Contemporánea. Medellín, Colombia: Eafit.

Derrida, J. (2001). Le siècle et le pardon, entretien avec Michel Wieviorka. Paris, France: Seuil.

Foucault, M. (1966). Las palabras y las cosas. Paris, France: Gallimard.

García, G. (2003). La literatura testimonial latinoamericana. (Re) presentación y (auto) construcción del sujeto subalterno. Madrid: Editorial Pliegos.

Garrido Rodríguez, E (2008). El perdón en procesos de reconciliación: el mecanismo micropolítico del aprendizaje para la convivencia. Revista Papel Político, 13.

Gómez, A. (2006). La guerra persistente. Memoria, violencia y utopía: representaciones contemporáneas de la guerra civil española. Madrid: Iberoamericana- Vervuert.

Hoyos, J. J. (2007). Escribiendo historias. El arte y el oficio de narrar en el periodismo. Medellín, Colombia: Universidad de Antioquia.
Huyssen, A. (2002). En busca del futuro perdido. Cultura y memoria en tiempos de globalización. México: Fondo de Cultura Económica.

López, F. (2005). La investigación cualitativa. Definición, riesgos y posibilidades. Medellín, Colombia: Universidad Autónoma Latinoamericana.

Lozano, E. y Ramírez, A. F. (2015). Eficacia normativa en materia tributaria. Revista de Derecho Público, 35, 4-23.

Martínez, T. E. (1997). Periodismo y Narración: desafíos para el siglo XXI. Conferencia.. En Hoyos, J J. (2007). Escribiendo historias. El arte y el oficio de narrar en el periodismo. Medellín, Colombia: Universidad de Antioquia.

Montero, R. (2016). La carne. Madrid: Alfaguara.

Nieves, G. M. (2015) El perdón contemporáneo y el retorno a la dimensión espiritual. De los mayores crímenes a la infinitud del perdón. Fragmentos de Filosofía, 13, 145-162.

Nussbaum, M. (2001). El cultivo de la humanidad, una defensa clásica de la reforma en la educación liberal. España: Editorial Andrés Bello.

Nussbaum, M. (2005). El conocimiento del amor. Ensayos sobre filosofía y literatura. Madrid: Antonio Machado Libros.

Proust, M. (1993). En busca del tiempo perdido: El tiempo recobrado. Madrid: Alianza.

Puerta Molina, A. A. (2009). Una voz de los olvidados. Análisis del periodismo narrativo de José Antonio Osorio Lizarazo. Journalism students in new media. Anagramas -Rumbos y sentidos de la comunicación-, 7 (14), 63-80. En línea. Recuperado de: http://www.scielo.org.co/ scielo.php?script=sci 
Ramírez, L. E. y otros. (2004). Paradigmas y modelos de investigación. Guía didáctica y módulo. Medellín, Colombia: Fundación Universitaria Luis Amigó.

Rodríguez Freyle, J. (1974). Ficciones de El carnero. Bogotá: Biblioteca colombiana literaria. En Correa, C. M. (2011). La crónica reina sin corona. Periodismo y literatura: fecundaciones mutuas. Medellín, Colombia: Fondo Editorial Eafit.

Rueda, C. (2012) Perdón y arrepentimiento: La experiencia de Jean Améry. Revista Ideas y Valores, LXI (148), 79-99. En línea. Recuperado de: https://revistas. unal.edu.co/index.php/idval/issue/ view/3433

Saavedra G., E. y Castro R., A. (2007). La investigación cualitativa, una discusión presente. Revista Liberabit, 13, 63-69.

Spires, R. (2005). Una historia fantasmal: Soldados de Salamina de Javier Cercas. La pluralidad narrativa. Escritores españoles contemporáneos (1984-2004). Madrid: Biblioteca Nueva.

Suárez, J. E. (2011). La literatura testimonial de las guerras en Colombia: entre la memoria, la cultura, las violencias y la literatura. Universitas Humanística, 72 (julio-diciembre).

Tacca, O. (1973). Las voces de la novela. Buenos Aires, Argentina: Gredos.

Theodosíadis, F. (1996). Literatura testimonial. Análisis de un discurso periférico. Bogotá, Colombia: Cooperativa Editorial Magisterio.

Vásquez, J. G, (2009). El arte de la distorsión. Bogotá, Colombia: Alfaguara.

Vargas Ll, M. (2015). Cartas a un joven novelista. Bogotá, Colombia: Debolsillo.

Vargas Ll, M. (2015). Elogio de la educación. Bogotá, Colombia: Taurus.

Villoro, Juan (2006). La crónica, ornitorrinco de la prosa. La nación, (22 de enero). En línea. Recuperado de: htto://www. lanacion.com.ar

Villanueva Chang, J. (2006). Un día con Julio Villanueva. Aragón: Asociación de la Prensa de Aragón. Congreso de periodismo digital.

Whitman, W. (1979). Hojas de hierba. Traducción de Francisco Alexander. Barcelona: Editorial Navarro. 